\title{
A EXTRAÇÃO DA VERDADE E AS TÉCNICAS INQUISITÓRIAS VOLTADAS PARA A CRIANÇA \\ E O ADOLESCENTE
}

\author{
Klelia Canabrava Aleixo*
}

\section{RESUMO}

O artigo traz reflexões sobre o substitutivo ao projeto de lei no 4.126 de 2004 , que dispõe sobre o procedimento de inquirição de crianças e/ou adolescentes vítimas ou testemunhas de crimes. A apuração da "verdade real" é apresentada como um dos seus objetivos e como ideal que legitima o aprimoramento de novas tecnologias inquisitórias voltadas para o público infanto-juvenil. A utilização de técnicas dessa natureza implica na abordagem da criança e do adolescente como objeto de investigação e não como sujeito de direitos.

Palavras-chave: verdade; inquirição; criança; adolescente.

\section{AbSTRACT}

TRUTH EXTRACTION AND INQUIRY TECHNIQUES DIRECTED TO CHILDREN AND ADOLESCENTS

The article brings considerations regarding the substitute of the bill of law $n^{\circ} 4.126$ of 2004, which lays out the inquiry procedures for children andlor adolescents who are victims or witnesses of crimes. The search for the "real truth" is presented as one of its objectives and as an ideal which legitimizes the improvement of new inquiry technologies directed to childrenlyoung adults. The use of techniques of such nature implies on the approach of the child and adolescent as objects of investigation and not as subjects of rights.

Keywords: truth; inquiry; children; adolescents.

* Professora da Faculdade Mineira de Direito da Pontifícia Universidade Católica de Minas Gerais (PUC-MG). 


\section{INTRODUÇÃO}

O presente artigo visa compartilhar algumas reflexões sobre o substitutivo ao projeto de Lei no 4.126 de 2004, que dispõe sobre o procedimento de inquirição das crianças e/ou adolescentes vítimas ou testemunhas de crime.

A necessidade da reflexão e discussão sobre o tema justifica-se pelo fato de que, se aprovado, o referido substitutivo legitimará o emprego da técnica, alcunhada de "Depoimento sem Dano", nas varas criminais de todo o Brasil.

No sentido de situá-las, alguns aspectos gerais do substitutivo serão apresentados. Em seguida, a discussão centralizar-se-á nos seus objetivos, em especial na questão da apuração da "verdade real" no processo penal e suas implicações nos processos envolvendo crianças e/ou adolescentes vítimas ou testemunhas de crimes.

Por fim, a técnica descrita no substitutivo analisado será identificada como inquisitória, tendo sido elaborada especificamente para o público infanto-juvenil com vistas à extração da verdade.

\section{AspeCtos GerAIS DO SUBSTITUTIVO}

O substitutivo ao projeto de lei no 4.126 , de 2004, dispõe sobre a inquirição de crianças e/ou adolescentes, vítimas ou testemunhas de crime, e produção antecipada de prova.

Contempla a possibilidade de utilização da técnica, alcunhada de "Depoimento sem Dano", não apenas na apuração de crimes de natureza sexual que envolvam crianças e/ou adolescentes como vítimas ou testemunhas, mas, também, nas hipóteses de crimes de natureza diversa (art. 197-B, parágrafo único). Portanto, trata de dispositivo que poderá ser largamente utilizado nas varas criminais do país.

No âmbito do Estatuto da Criança e do Adolescente (Lei no 8.069 de 13 de julho de 1990), acrescenta a seção VIII ao capítulo III do Título I (Do Acesso à Justiça), dispondo sobre o procedimento de inquirição da criança e do adolescente para a produção de prova em processo penal.

Conforme observa Esther Arantes (2008), trata-se de regulamentação de matéria nova, "uma vez que em lugar algum o Estatuto menciona que crianças e adolescentes devam ser inquiridos judicialmente para produção antecipada de prova, seja como vítima ou testemunha" (Arantes, 2008: 2).

O Estatuto assegura no art. 16, inciso II, o direito de opinião e de expressão como corolário do direito à liberdade de crianças e adolescentes. O direito de 
opinião consiste na liberdade de possuir convicções próprias e o direito de expressão na liberdade de exteriorização ou manifestação do pensamento. Trata-se dos "direitos comunicativos de liberdade" (Baratta, 1999: 51).

A técnica da inquirição "designa, na terminologia jurídica, o ato de se obterem informações a respeito de certos fatos, de pessoas que se presumem sabê-los, por meio de perguntas feitas às mesmas" (Silva, 2000: 434).

$\mathrm{O}$ direito de opinar e expressar-se configura formas de manifestaçôes espontâneas, que emanam do próprio titular do direito, na hipótese, crianças e adolescentes.

Conforme ensina Alessandro Baratta (1999), ao comentar o art. 12 da Convenção Internacional sobre os Direitos da Criança, o direito da criança de fazer um juízo próprio e de expressar-se implica no dever simétrico dos adultos de escutála. Isso significa, "el deber del adulto de aprender de los niños, es decir, de penetrar cuanto sea posible al interior de la perspectiva de los niños, medir a través de ello la validez de sus propias (del adulto) opiniones y actitudes y estar dispuesto a modificarlas" (Baratta, 1999: 53).

A técnica da inquirição, seja ela qual for, parte de uma concepção utilitária da obtenção da informação voltada para a constituição da prova no processo judicial e conseqüente responsabilização do agressor. Nesse sentido, ela subestima a amplitude do direito à opinião e expressão de crianças e adolescentes e viabiliza uma relação bem restrita entre estes e os adultos.

Sobre a relativização do exercício do direito de opinião e de expressão no sistema de justiça, Leila Brito, Lygia Ayres e Marcia Amendola (2006) observam que a fala de crianças e adolescentes vem sendo sistematicamente solicitada e valorizada em determinadas situações, como as que envolvem denúncias de abuso sexual e disputas de guarda. No entanto, a fala dos que cumprem medidas socioeducativas e dos que se encontram abrigados não se apresenta com igual valor:

No primeiro caso temos pais calados e crianças que falam, ou cujos desejos devem decidir questōes jurídicas em nome de seus direitos. No segundo grupo, vozes caladas, sem eco, cujos pais, na maior parte das vezes, também já foram calados pelo aparelho de Estado, no qual o som de suas vozes não possui volume suficiente para se fazer valer, ou, quem sabe, argüir sobre os direitos de suas crianças, retirando-as das amarras do Estado (Brito, Ayres \& Amendola, 2006: 2).

Dentre os objetivos expressos no art. 197-A do substitutivo em comento, a inquirição judicial de criança e adolescente visa salvaguardar a sua integridade enquanto depoente, considerada a sua condição peculiar de pessoa em desenvol- 
vimento; evitar a sua sobrevitimização; evitar que a perda da memória dos fatos prejudique a apuração da verdade real.

\section{A APURAÇÃo dA “VERDAdE REAL" NO PROCESSO PENAL ENVOLVENDO A CRIANÇA E O ADOLESCENTE}

A busca da verdade sempre esteve presente no campo da existência humana e do conhecimento científico. Enquanto fundamento do conhecimento, "ela aparece no momento em que as certezas da doxa se esvaem e as verdades do mito não se revelam mais capazes de impor suas evidências aos homens" (Domingues, 1991: 363).

$\mathrm{Na}$ passagem do mito ao logos, a exigência da prova da verdade se deu pelo fato de a palavra se vincular à coisa apenas através de uma mediação, do pensamento.

Sob este lastro, a constante investigação sobre a verdade se instala no sentido de saber se a "representação é conforme à coisa ou o de provar que o discurso revela o em si da coisa ou sua realidade fundamental" (Domingues, 1991: 365).

No âmbito do direito processual penal, a busca da verdade consiste em saber "se aconteceu ou não aconteceu determinado fato: um homem foi ou não foi assassinado, uma mulher foi ou não foi violentada, um documento foi ou não foi falsificado, uma jóia foi ou não foi levada embora?” (Carnelutti, 1995: 43).

A idéia de que o conhecimento da verdade possa ser alcançado através do processo, suas técnicas e discurso, surgiu no período da inquisição. A partir de então, tal crença é responsável pela ausência de limites do Estado na atividade de investigação, culminando com a permanência da tortura e da figura do juiz inquisidor até os dias atuais.

Em nome da "verdade real", o substitutivo ao projeto de lei disciplina no art. 197-B que a inquirição da criança ou do adolescente seja feita em recinto diverso da sala de audiência, especialmente projetado para esse fim, contendo os equipamentos próprios e adequados à sua idade e etapa evolutiva.

Para tal mister, idealizou-se um local em que um profissional (psicólogo ou assistente social) se ponha a inquirir a criança ou adolescente reproduzindo as perguntas formuladas pelo juiz e transmitidas por meio de um ponto eletrônico.

A presença de "equipamentos próprios", ou seja, brinquedos ou artefatos do gênero, consiste em autêntico aprimoramento de tecnologia inquisitória, elaborada especificamente para o público infanto-juvenil. Com vistas à extração da "verdade", funcionam como desviantes da atenção da criança ou do adolescente acerca do que realmente está ocorrendo (a sua inquirição). 
Na medida em que esconde o juiz, o promotor, o advogado e eventualmente o réu - os quais estariam na sala de audiências observando a inquirição, sem serem vistos -, pode induzir a criança a acreditar que está em companhia apenas de uma pessoa de sua confiança.

Trata-se, pois, do aprimoramento de técnicas inquisitórias que perpassam pela supressão do princípio da dignidade e do respeito à criança e ao adolescente, submetendo-os a uma teatrologia que subverte o próprio papel do psicólogo, do assistente social e suas intervenções profissionais.

Ocultada pelo mito da "verdade real", a busca pela responsabilização do agressor é expressa e reiteradamente ressaltada na "Justificação" do substitutivo do projeto de lei. No entanto, tal responsabilização não pode se dar a partir da abordagem da criança e do adolescente como objeto de investigação.

Necessário se faz discutir acerca da instrumentalização utilizada na produção de prova judicial em que a criança ou adolescente é exposta a câmeras filmadoras. Alega-se que a filmagem do seu depoimento evita a revitimização, decorrente de sucessivas inquirições sobre o mesmo fato.

Tal exposição não seria mais uma forma de violência, uma vez que a história da criança ou do adolescente é gravada, eternizando-se dessa forma a sua própria condição de vítima?

A propósito, não há no substitutivo nenhuma determinação de como será feita a segurança destas gravações.

Interessante observar que, em busca da responsabilização do agressor, o Estado não canaliza as mesmas tecnologias para a diminuição dos danos sofridos pela criança e pelo adolescente quando da ocorrência do próprio ato delituoso. Ao estabelecer essa "moderna" forma inquisitória, com a intervenção de técnicos previamente preparados para tal, o que se constata é a ratificação dos propósitos punitivos do Estado e sua índole negligente em face dos fenômenos vitimógenos acarretados pelo ato delituoso em si, vale dizer, as conseqüências do abuso, que foram relegadas a um plano inferior.

Em nome da "verdade real", o art. 197-D do projeto de lei autoriza o juiz a determinar de ofício a produção de prova, antes mesmo da existência do processo penal. Permite-se ao juiz que atue como parte na produção da prova, recolhendo material que vai constituir o seu convencimento, o que compromete de maneira irreparável a sua imparcialidade no julgamento da causa. Nesse contexto, o acusado também perde a sua posição de sujeito de direitos e é convertido em mero objeto de investigação.

A partir de Francesco Carnelutti (1995), faz-se necessário reconhecer que a verdade é algo inatingível. Por isso, "é o processo penal, em si, uma pobre coisa, à 
qual é destinada uma tarefa muito alta para ser cumprida" (Carnelutti, 1995: 52). Nesse sentido, ele identifica o processo penal como um instituto "no qual se revelam todas as deficiências e as impotências do direito...” (Carnelutti, 1995: 90).

Piero Calamandrei (1997), em sua clássica obra Elogio dei giudici scritto da un avvocato, assinala a complexidade que envolve a questão da verdade:

Há, num museu de Londres, um quadro do famoso pintor Champaigne, no qual se pintou o Cardeal Richelieu em três atitudes diferentes. Ao centro da tela, vemo-lo de frente, aos lados vemo-lo de perfil a olhar para o centro. O modelo é um só, mas na tela parece que são três pessoas a conversar, de tal modo que são diferentes as expressões das figuras vistas de perfil e, mais do que isto, o ar calmo que, no retrato do centro, é a síntese dessas duas figuras (Calamandrei, 1997: 96).

Calamandrei (1997) valeu-se do quadro de Champaigne para demonstrar que todo objeto se apresenta com mais de um ângulo e cada um destes reflete a sua verdade, sem que nenhuma delas seja absoluta.

Nietzsche ([1888] 2008) observa que considerando-se o que a humanidade tomou como importante até o momento, o conceito de "verdade", assim como outros conceitos "não são sequer realidade, apenas construções; expresso com mais rigor, mentiras...” (Nietzsche, [1888] 2008: 47). Assim, com relação ao fato criminoso e sua investigação pelo direito, sendo um evento passado, não é passível de experiência direta, implicando a sua busca no presente em inevitável construção.

Em seu livro As verdades e as formas jurídicas, Michel Foucault ([1973] 1999) discorre sobre os "modelos de verdades" presentes nas práticas jurídicas, "lugares onde a verdade se forma, onde um certo número de regras de jogo são definidas" (Foucault, [1973] 1999: 11). Para este autor, a verdade também é entendida como algo construído, não como algo etéreo, abstrato e puro.

Ao dissertar sobre o direito feudal, Foucault ([1973] 1999) explicita que nas práticas jurídicas a prova não tinha a função de fazer aparecer a verdade, mas de estabelecer que o mais forte era, ao mesmo tempo, quem tinha razão. Acompanhando a história do direito, observa que toda a segunda metade da Idade Média foi marcada pelo surgimento de novos procedimentos judiciários:

Se a principal vítima de uma infração é o rei, se é o procurador que se queixa em primeiro lugar, compreende-se que a liquidação judiciária não pode mais ser obtida pelos mecanismos da prova. O rei ou seu representante, o procurador, não podem arriscar suas próprias vidas ou seus próprios bens cada vez que um 
crime é cometido. Não é em pé de igualdade, como em uma luta entre dois indivíduos, que o acusado e o procurador se defrontam. É preciso encontrar um novo mecanismo que não seja mais o da prova, da luta entre dois adversários, para saber se alguém é culpado ou não. $\mathrm{O}$ modelo belicoso não pode ser mais aplicado (Foucault, [1973] 1999: 67).

$\mathrm{O}$ inquérito surge, então, como substitutivo da prova. Trata-se do modelo de inquérito que existiu na época do Império Carolíngio:

O representante do poder chamava pessoas consideradas capazes de conhecer os costumes, o Direito ou os títulos de propriedade. Reunia estas pessoas, fazia com que jurassem dizer a verdade, o que conheciam, o que tinham visto ou o que sabiam por ter ouvido dizer. Em seguida, deixadas a sós, estas poucas pessoas deliberavam. Ao final dessa deliberação pedia-se a solução do problema (Foucault, [1973] 1999: 69).

A verdade era determinada pelo poder político, pelos procuradores do rei. $\mathrm{O}$ inquérito judiciário era uma maneira de se exercer o poder e se difundiu em muitos outros domínios do saber. "Foi assim que, graças a inquéritos sobre o estado da população, o nível das riquezas, a quantidade de dinheiro e de recursos, os agentes reais asseguraram, estabeleceram e aumentaram o poder real" (Foucault, [1973] 1999: 74). Deste modo, a partir de Foucault, percebe-se que a verdade não é conhecida e sim estabelecida pelos procedimentos jurídicos que estruturam o poder.

Aliada às questóes acerca da busca da "verdade real" no processo penal, sobre a qualidade dos fatos narrados no depoimento de crianças, Lopes Júnior e Di Gesu (2007) observam que "a tendência infantil é justamente a de corresponder às expectativas do que deveria acontecer, bem como às expectativas do adulto entrevistador" (Lopes Júnior \& Di Gesu, 2007: 2). Baseados nos estudos de Binet, estes autores apontam também a existência de numerosos erros involuntários de crianças submetidas a testes de recordação (Lopes Júnior \& Di Gesu, 2007).

Nesse contexto, a inquirição judicial da criança e do adolescente em busca da "verdade real" não implica na garantia da sua integridade e sobrevitimização, mas no seu tratamento como objeto de investigação voltado para a responsabilização do agressor.

\section{CONSIDERAÇÕES FINAIS}

A apuração da "verdade real" traz diversas implicações nos processos envolvendo crianças e/ou adolescentes vítimas ou testemunhas de crimes. 
A inquirição da criança e/ou do adolescente em recinto diverso da sala de audiências, dotado de equipamentos próprios à sua idade e realizada por técnico que reproduz as perguntas formuladas pelo juiz por meio de um ponto eletrônico, consiste em autêntico aprimoramento de tecnologias inquisitórias elaboradas especificamente para o público infanto-juvenil com vistas à extração da verdade.

O emprego desta técnica não implica na garantia do direito de opinião e de expressão da criança e do adolescente, dado que a inquirição parte de uma concepção utilitária da obtenção da informação voltada para a produção de prova em processo judicial.

Submetendo a criança e/ou adolescente a uma teatrologia que subverte o próprio papel do psicólogo, do assistente social e de suas intervenções, o emprego de tecnologias dessa natureza perpassa pela supressão dos princípios da dignidade e do respeito aos envolvidos.

Nesse contexto, o objetivo da apuração da "verdade real" pelo processo que envolve a criança e/ou o adolescente como vítima ou testemunha de crime legitima a sua abordagem como objeto de investigação.

A filmagem do seu depoimento, além de não evitar a sobrevitimização decorrente de sucessivas inquirições sobre o mesmo fato, eterniza a sua própria condição de vítima cujas imagem e história são gravadas em CD-Rom.

Em busca da responsabilização do agressor, o substitutivo não prioriza a diminuição dos danos sofridos pela criança e pelo adolescente quando da ocorrência do próprio ato delituoso, já que reduz a atividade do psicólogo e do assistente social à de mero inquiridor.

Faz-se necessário reconhecer que, no âmbito do processo penal, a apuração da verdade é algo inatingível. Sendo o crime um fato passado, não é passível de experiência direta, implicando a sua busca no presente em inevitável construção.

Portanto, a prova produzida pela técnica descrita no substitutivo analisado implica na abordagem da criança e do adolescente como objeto do direito, voltada sob o viés punitivo para a responsabilização do agressor.

\section{REFERÊNCIAS BIBLIOGRÁFICAS}

Arantes, E. M. de M. (2008). Consideraçōes sobre o substitutivo ao projeto de lei no 4126 de 2004. Texto apresentado em audiência pública no Senado Federal, Brasília, DF. Baratta, A. (1999). Infancia y Democracia. Em García Mendez, E. (org). Infância, Ley y Democracia (pp. 31-57). Buenos Aires: Editoria Temis. 
Brito, L.; Ayres, L. \& Amendola, M. (2006). A escuta de crianças no sistema de justiça. Psicologia \& Sociedade, 18, 3, 1-15.

Calamandrei, P. (1997). Eles, os juizes, vistos por um advogado. Lisboa: Livraria Clássica. Carnelutti, F. (1995). As misérias do processo penal. São Paulo: Conan.

Domingues, I. (1991). O grau zero do conhecimento: o problema da fundamentação das ciências humanas. São Paulo: Loyola.

Foucault, M. (1973). As verdades e as formas jurídicas. Rio de Janeiro: Nau, 1999.

Lopes Júnior, A. \& Di Gesu, C. C. (2007). Prova penal e falsas memórias: em busca da redução de danos. Boletim IBCCRIM, 175, 1-5.

Nietzsche, F. (1888). Ecce Homo: como alguém se torna o que é. São Paulo: Companhia das Letras, 2008.

Silva, De P. e. (2000). Vocabulário Jurídico. Rio de Janeiro: Forense.

Recebido em 15 de abril de 2008 Aceito para publicação em 12 de setembro de 2008 